Harald Bluhm, Karsten Fischer, Marcus Llanque (Hg.)

\title{
Ideenpolitik
}

Geschichtliche Konstellationen und gegenwärtige Konflikte

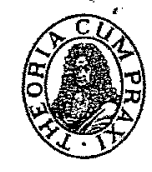

Akademie Verlag 


\section{Religion und politischer Eid im 19. und 20. Jahrhundert}

Es gibt nur weniges, was in der bürgerlichen Welt unangenehmer ist als die eidesstattliche Erklärung. Rechtlich in vielen Gebieten angewandt, ist sie in der Allgemeinheit vor allem als Offenbarungseid, wie es früher hieß, bekannt. Einerseits entschuldet er den Versichernden, andererseits stößt er ihn aus dem Kreis der bürgerlichen Wirtschaftssubjekte aus. Ein Wirtschaftsbürger ist der den Offenbarungseid Leistende nicht mehr. Dieser dramatische soziale Akt beruhte auf der juridischen strafbewährten Form des Eides. Der Eid diente dazu, richtiges Wissen zu erhalten, um darauf das richterliche Urteil gründen zu können. Arthur Schopenhauer hatte den Eid 1856 deshalb eine ,metaphysische Eselsbrücke des Juristen" genannt. Das Gericht durfte und musste alles, was unter Eid ausgesagt war, als richtig annehmen. ${ }^{1}$

Der Eid spielte jedoch nicht nur im Verhältnis der Bürger untereinander, sondern auch im Verhältnis zum politischen Gemeinwesen eine wichtige Rolle. Für die politische Dimension des Eides ist sein Verhältnis zum Amt zentral. Der Grundbegriff der politisch-sozialen Sprache „Amt ${ }^{\text {ts }}$ besitzt einen religiösen Subtext. Die Unterscheidung zwischen Amtsinhaber und personenungebundener Ämterordnung war grundlegend für den modernen Staat. Historisch bildete sich diese Trennung zuerst in der Kirche aus. Priester wurden gleichsam zu den ersten Beamten. Um ein herausgehobenes öffentliches Amt zu erlangen, war und ist es nötig, einen politischen Eid zu leisten. Es verrät viel über die Geschichte des politischen Eides, dass sich die Öffentlichkeit bei jeder Kabinettsvereidigung stark dafür interessiert, welche Minister die religiöse Eidesformel gebrauchen und welche es nicht tun. Der Eid verpflichtet die Eidleistenden auf die Normen des Gemeinwesens. Dass der Einzelne einen politischen Eid leistet, sagt nicht nur etwas über die gesellschaftliche Bindewirkung des Eides aus, sondern auch über das Verhältnis von Individuum und Religion, von Individuum und Staat sowie von Staat und Kirche. Der Eid ist an der Schnittstelle von Religion und Politik angesiedelt. Die religiöse Dimension des Eides ist beschrieben worden als „bedingte Selbstverfluchung“, weil die angerufene religiöse Instanz den gebrochenen Eid rächt. Davon legt besonders eindrucksvoll die Sprache der Märchen Zeugnis ab. Dort fallen Schwurfinger ab oder

1 Arthur Schopenhauer, Parerga und Paralipomena, hrsg. v. Julius Frauenstädt, Leipzig 1922, §134, 175; vgl. Paolo Prodi, Das Sakrament der Herrschaft. Der politische Eid in der Verfassungsgeschichte des Okzidents, a.d. Ital. v. Judith Elze, Berlin 1997, 413; Thomas Börsch, Eidesstattliche Versicherung. Strafrechtliche Bedeutung einer Formhülse, Münster 2009. 
werden schwarz. Gleichzeitig zeigt die Vorstellung der „bedingten Selbstverfluchung“ die Nähe des Eides zu einem magischen Verständnis von Religion. ${ }^{2}$ Mit Blick auf seine öffentliche Bedeutung galt der Eid bis ins 19. Jahrhundert als ,vinculum societatis". Dahinter stand die Überzeugung, dass die soziale und die politische Ordnung nur erhalten werden könne, wenn sich die Bürger gegenseitig durch Eide sicherten. ${ }^{3}$

Eide werden kategorisiert in assertorische und promissorische Eide. Assertorische Eide dienen der Sicherstellung von Sachverhalten im Rechtswesen. Sie waren und sind immer noch ein Institut weltlicher Rechtsordnungen. ${ }^{4}$ Promissorische Eide beschwören dagegen Treue und Gefolgschaft. Ein Meineid ist nur bei einem assertorischen Eid möglich. Bei promissorischen Eiden gibt es den Eidesbruch. Der politische Eid ist ein promissorischer Eid, der das Treueverhältnis zum politischen Gemeinwesen absichern soll. Historisch ist der politische Eid besonders am Beispiel des „Führereides" und seinem Bruch durch die Verschwörer vom 20. Juli 1944 prominent. Wie konnten eidverpflichtete Offiziere Widerstand gegen den Eidnehmer leisten? Weil dadurch die Gewissensbindung durch den Eid besonders sichtbar wurde, kam es für das Attentat vom 20. Juli 1944 zur Bezeichnung ,Aufstand des Gewissens.".

Unter dem Einfluss der Säkularisierungstheorie dominierte in der Literatur lange Zeit die These des Niedergangs des politischen Eides. Aus dem Eid auf einen Vertrag sei eine Art säkularisiertes Gelübde zur Verpflichtung auf ein Amt oder auf die Amtspflichten, aus dem Eid die eidesstattliche Versicherung oder eine Art säkulare Beteuerungsformel geworden. ${ }^{6}$ Ernst Friesenhahn, Autor der wichtigsten Studie zum politischen Eid, bezweifelte gar die Angemessenheit des politischen Eides in der Gegenwart. Für ihn blieb die Frage offen, „ob politische Eide [...] den für eine lebendige Demokra-

2 Vgl. Wolfgang Brückner, Artikel „Eid, Meineid“, in Enzyklopädie des Märchens, Bd. 3, Berlin 1981, 1132 (Beispiele: Speculum laicorum; Johannes Pauli; Andreas Hondorff Otho Melander).

3 Vgl. hierzu Michael Maurer, ,Religiöse Eide zur Sicherung politischer Loyalität in England, Irland und Schottland im Konfessionellen Zeitalter", in Albrecht Beutel u.a. (Hrsg.), Aufgeklärtes Christentum, Leipzig 2010, 302f; André Holenstein, „Seelenheil und Untertanenpflicht. Zur gesellschaftlichen Funktion und theoretischen Begründung des Eides in der ständischen Gesellschaft", in Peter Blickle (Hrsg.), Der Fluch und der Eid. Die metaphysische Begründung gesellschaftlichen Zusammenlebens und politische Ordnung in der ständischen Gesellschaft, Berlin 1993; Klaus Schreiner, „Rechtgläubigkeit als ,Band der Gesellschaft', und ,Grundlage des Staates". Zur eidlichen Verpflichtung von Staats-und Kirchendienern auf die ,Formula concordiae, und das Konkordienbuch", in Martin Brecht (Hrsg.), Bekenntnis und Einheit der Kirche, Stuttgart 1980; allgemein: Giorgio Agamben, Das Sakrament der Sprache. Eine Archäologie des Eides, (Homo Sacer II,3), Frankfurt a.M. 2010.

Vgl. Peter Landau, „Eid V“, in Theologische Realenzyklopädie, Bd. 9, Berlin 1982, 390.

5 Vgl, allgemein: Sven Lange, Der Fahneneid. Die Geschichte der Schwurverpflichtung im deutschen Heer, Bremen 2003; Militärgeschichtliches Forschungsamt (Hrsg.), Aufstand des Gewissens. Militärischer Widerstand gegen Hitler und das NS-Regime 1933 bis 1945, hrsg. v. Thomas Vogel, Hamburg u. Berlin 2000.

6 Vgl. Michael Rutschky, „In Treue fest. Das Spiel der Loyalitäten“", in Merkur, 61, 696, 2007; Werner Schöllgen, „Der politische Eid“, in Ders., Aktuelle Moralprobleme, Düsseldorf 1955, 230ff; Ders., „Der politische Eid“, in Hochland, 40, 3, 1948. 
tie unentbehrlichen politischen Consensus schaffen können oder nicht vielmehr seine Existenz in nuce voraussetzen und ihn nur bewusst machen und verstärken können".?

Dieser Zusammenhang von Säkularisierung, Amt und Eid soll im Folgenden problematisiert werden. Ausgangspunkt ist dabei die Beobachtung, dass der Eid nicht nur eine religiös-semantische, sondern vor allem eine performative Dimension hat, die ihn implizit zu einem religiösen Akt macht. Die Säkularisierung des Eides betrifft also, anders als zumeist angenommen, nicht nur die Eidesformel, sondern den Eid als solchen. Der Sakralsphäre war auch dann kaum zu entkommen, wenn Eidesformeln ohne religiöse Wendung verlangt wurden. Die Geschichte der religiösen Eidesformeln und des Eides ist daher auch Teil einer Geschichte des politischen Imaginären, das für die politische Stabilität notwendig bleibt. ${ }^{8}$ Wer will, kann weitergehen und darin einen Beleg für Carl Schmitts These sehen, alle politischen Begriffe seien säkularisierte theologische Begriffe. $^{9}$

Vor dem Hintergrund dieser Überlegung zeichne ich den Wandel der religiösen Eidesformeln in zwei Schritten nach: Erstens von den konfessionellen zu den allgemeinreligiösen Formeln, zweitens von diesen zur nicht-religiösen Eidesformel der Weimarer Republik. Gezeigt werden soll, dass die voranschreitende Entfremdung von Staat und Kirche erstaunlicherweise wesentlich auf der Basis des politischen Eides erfolgte, der implizit und performativ einen religiösen Bedeutungshorizont aufrief.

\section{Amt und Eid}

Für die neueste deutsche Geschichte ist kennzeichnend, dass die Ausübung eines Amtes an sozialmoralische Voraussetzungen gebunden war. Im Kaiserreich war dies in erster Linie die protestantische politische Ethik. Die politisch-bürgerliche Sittlichkeit des Protestantismus umschrieb der Theologe Martin Kähler 1872 mit Gehorsam und Pflichttreue, Intelligenz, Sachlichkeit und Toleranz, alles Gegenstände einer protestantischen Erziehung. ${ }^{10}$ Eine ganze Generation protestantischer Theologen betonte diese Hingabe an das Ganze und unterstrich die protestantische Färbung des Amtsgedankens. ${ }^{11}$ Im Wörterbuch der deutschen Sprache von 1860 wurden als sinnverwandte

7 Ernst Friesenhahn, „Zur Problematik des politischen Eides“, in Zeitschrift für Schweizerisches Recht 99, 1980, 3f.

8 Vgl. Albrecht Koschorke, „Staaten und ihre Feinde. Ein Versuch über das Imaginäre der Politik“, in Jörg Huber (Hrsg.), Einbildungen (Interventionen 14), Zürich 2005.

9 Vgl. Carl Schmitt, Politische Theologie. Vier Kapitel zur Lehre von der Staatssouveränität, Berlin 1993.

10 Vgl. Martin Kähler, Die starken Wurzeln unserer Kraft. Betrachtungen über die Begründung des Deutschen Kaiserreiches und seine erste Krise, Gotha 1872.

11 Vgl. Horst Dreier, Kanonistik und Konfessionalisierung. Marksteine auf dem Weg zum Staat, 145f; Ernst Wolfgang Böckenförde, „Kirche und modernes Bewusstsein“, in Peter Koslowski u.a. (Hrsg.), Moderne oder Postmoderne? Zur Signatur des gegenwärtigen Zeitalters, Weinheim 1986, 114. 
Begriffe für Amt angegeben: Pflicht, Schuldigkeit, Obliegenheit und Beruf. ${ }^{12}$ Auch Lorenz von Stein sah den Sinn des Amtes in „einer höheren Erhebung", in einem ,edleren, sittlichen, das Amt wahrhaft belebenden und erwärmenden Standpunkt ${ }^{c c} .{ }^{13}$ Das Am: kannte ein bestimmtes Pathos, was es deutlich von den aufsteigenden Sozialfiguren des Managers und des Funktionärs abhob. ${ }^{14}$

Im Eid ging es um die Gewissensbindung und die Selbstverpflichtung des Amtstra:gers. Das wertgebundene weltanschauliche Unterfutter der Institution ,Amt ${ }^{*}$ musste öffentlich zelebriert und beschworen werden. Erst dann konnte es geglaubt werden im Sinne von Max Webers Legitimitätsglauben. Nur so gelangte ein Amtsinhaber in ,Amt und Würden". Der politische Eid bestätigte die Ämterordnung und verwandelte gleichzeitig die Person des Eidleistenden in einen Amtsinhaber. Der Eid konsekrierte - in der Theoriesprache von Pierre Bourdieu - als Endstufe eines Auswahlprozesses die Persore zum Amtsinhaber. ${ }^{15}$ Aus der Sicht des Staates verankerte der Eid seine Institutionen im Gewissen seiner Bürger. Besonders beim Wechsel politischer Systeme kam dem politischen Eid die Funktion zu, das ,willkürlich" Erzeugte der Willkür zu entziehen, im Gewissen der Bürger zu verankern und unantastbar zu machen. Dem Konstitutionalismus des 19. Jahrhunderts war dies durch den Verfassungseid gelungen. ${ }^{16}$ Beim Übergang von der Monarchie in die Weimarer Republik sollte diese Aufgabe der religionslose Eid leisten.

\section{Konfessionelle Eidesformeln}

Wer in Amt und Würden gelangen wollte, kam bis in das Kaiserreich hinein nicht daran vorbei, mit konfessionellen Eidesformeln zu schwören. Das historische Staatsrecht sprach hier vom „Eideshort", bei dem geschworen wurde. Bis in das späte 19. Jahrhundert umfasste er dezidiert konfessionelle Inhalte, die das Gesamt des jeweiligen Konfessionssystems zur Distinktion aufriefen. Deutlich wurde dies in der Eidesformel der preußischen Armee vom 5. Juni 1831. Sie begann mit den Worten: „Ich schwöre zu Gott dem Allwissenden und Allmächtigen [...]“ und schloss mit: „So wahr mir Gott helfe". Evangelische Christen fügten hinzu: „durch Jesum Christum zur Seligkeit!" Katholiken beendeten den Eid mit den Worten: ,und sein heiliges Evangelium. Amen! ${ }^{\text {t }}$ Diese beiden Formeln gingen auf den Passauer Vertrag von 1552 und den Reichstags-

12 Vgl. Daniel Sanders, Wörterbuch der deutschen Sprache, Bd. 1, Leipzig 1860, 29f; Bernd Wunder, Artikel „Verwaltung“ in Geschichtliche Grundbegriffe, Bd. VII, Stuttgart 1992, 85.

13 Lorenz von Stein, Die Lehre von der vollziehenden Gewalt, ihr Recht und ihr Organismus: Mit Vergleichung der Rechtszustände von England, Frankreich und Deutschland, Stuttgart 1865, 284.

14 Vgl. Amold Köttgen, „Das anvertraute öffentliche Amt", in Konrad Hesse u.a. (Hrsg.), Staatsverfassung und Kirchenordnung. Festgabe für Rudolf Smend (80), Tübingen 1962, $127 \mathrm{f}$.

15 Zum Theorem der Konsekration vgl. Pierre Bourdieu, Die Regeln der Kunst. Genese und Struktur des literarischen Feldes. Frankfurt a. M. 1999; Ders., Rede und Antwort, Frankfurt a.M. 1992.

16 Zum Verfassungseid vgl. Dennis Bock, „Der Eid auf die Verfassung im deutschen Konstitutionalismus", in Zeitschrift der Savigny Stiftung für Rechtsgeschichte (Germanistische Abteilung), 123, 2006. 
abschied von 1555 zurück, die bestimmten, dass Eide künftig nur auf Gott und die Evangelien abzulegen seien. ${ }^{17}$

Konfessionelle Eidesformeln blieben bis ins späte 19. Jahrhundert hinein die Regel. Thre Symbolik kommunizierte die Bedeutung des politischen Eides in der Öffentlichkeit. Die drei Schwurfinger symbolisierten die drei göttlichen Personen. Sie umschlossen die beiden anderen Finger, die für die Seele und den menschlichen Leib standen. ${ }^{18}$ Darüber hinaus vergegenwärtigte die Symbolik drastisch die Folgen eines Meineides. Das reichte bis zur göttlichen Verfluchung. Dem kurzfristigen Gewinn, der dem Meineidigen aus seinem falsch abgelegten Eid erwuchs, standen ewige Sündenstrafen gegenüber. Der Meineid schloss ihn aus der Christenheit aus. Im Sterben musste er auf den göttlichen Trost verzichten und konnte nicht auf die göttliche Barmherzigkeit hoffen. Beim Jüngsten Gericht würde der strenge Richter ihn ewig verdammen. Wer also sein Seelenheil für eine Sache verpfändete, der musste es todernst meinen. ${ }^{19}$

Früh schon leisteten Wiedertäufer und Mennoniten Widerstand gegen diese Form der Produktion von Untertanenloyalität durch konfessionelle Eide. ${ }^{20}$ Dissentierende Gruppen und Sekten standen unter dem doppelten Druck des konfessionellen Gewissenszwanges und der politischen Untertanenpflicht. In der frühen Neuzeit nutzten die Territorialstaaten den Eid, um ihre Amtsträger auf das Gemeinwesen zu verpflichten. Konfessionell gemischte Staaten wie England stellten über den konfessionellen Eid ein politisch und religiös loyales Beamtentum her und schlossen Katholiken von öffentlichen Ämtern aus. Hier nahm der Eid die Form des politischen Eignungstestes an. Wer ihn nicht schwören konnte oder wollte, machte sich katholischer Neigungen verdächtig. Der „oath of supremacy“ und die „declaration against transsubstantiation" zogen scharfe Trennlinien zwischen zuverlässigen und unzuverlässigen Beamten. ${ }^{21}$ Bis 1829 hielten sie in England Katholiken von öffentlichen Ämtern und aus dem Parlament fern.

17 Vgl. Bopp, Artikel „Meineid“, in Staats-Lexikon oder Encyclopädie der Staatswissenschaften, Bd. 10, Altona $1845 \mathrm{ff}, 407$.

${ }^{18}$ Vgl. André Holenstein, Die Huldigung der Untertanen: Rechtskultur und Herrschaftsordnung (800-1800), Stuttgart 1991, 57; Ders., Seelenheil und Untertanenpflicht, 34.

19 Beispiele bei Holenstein, Seelenheil und Untertaneppficht, $35 \mathrm{f}$.

201848 unternahmen badische und andere Mennoniten zum wiederholten Mal einen Versuch, von der Eidesleistung befreit zu werden. Vgl. Rudolf Muhs, ,,Das schöne Erbe der frommen Väter ‘. Die Petition der badischen Mennoniten an die deutsche Nationalversammlung von 1848 um Befreiung von Eid und Wehrpflicht", in Mennonitische Geschichtsblätter, 42, 1985. Mennoniten waren im Kaiserreich in Preußen, Bayern, Württemberg und Elsass-Lothringen von der Eidesleistung befreit.

${ }^{21}$ Declaration against Transsubstantiation: „I do solemnly and sincerely [...] profess, testify and declare, that $I$ do believe, that in the Sacrament of the Lord's Supper there is not any Transsubstantiation of the Elements of Bread and Wine into the Body and Blood of Christ at or after the Consecration thereof by any Person whatsoever: And that the invocation or Adoration of the Virgin Mary or any other Saint and the Sacrifice of the Mass, as they are now used in the Church of Rome, are superstitous and idolatrous ${ }^{c}$. Der Oath of Supremacy verlangte das Bekenntnis, ,that I do from my heart abhor, detest and abjure as impious and heretical that damnable Doctrine, and Position that Princes excommunicated or deprived by the Pope or any authority of the See of Rome, may be deposed or murdered by their Subjects or any other whatsoever. And I do declare, that no foreign Prince, Person, Prelate, State or Potentate hath or ought to have any jurisdiction, Power, Superiorty, 
Zugleich sakralisierte der Eid die politische Herrschaft. Der italienische Verfassungshistoriker Paolo Prodi bezeichnete ihn als ein „Sakrament der Herrschaft", denn in ihm wurde ein Abstractum sinnenfällig. ${ }^{22}$ Gleichzeitig werteten Eide die politische Herrschaft sakral auf, indem sie ewige religiöse Strafen für den Fall androhten, dass man Widerstand gegen sie leistete. Herrschaftliche und genossenschaftliche Verbände konnten sich somit auf das Verhalten ihrer Mitglieder besser verlassen. Das Gleiche galt für alle von Ämtern getragenen Institutionen. Eide reproduzierten die Ämterordnung eines Gemeinwesens und sicherten seine Dauer: ${ }_{i}^{23}$

\section{Die politische Kritik der Eidesformeln}

Spätestens in den modernen Nationalstaaten geriet der politische Eid in die Kritik. Das hatte sich bereits im 18. Jahrhundert angedeutet. ${ }^{24}$ Denn während die religiöse Ethik Verpflichtungen durch eine höhere Ins̀tanz begründete, war der moderne Staat, zumal der Nationalstaat, für die Begründung seiner Forderung nach Loyalität abhängig vom Erfolg. ${ }^{25}$ Für den modernen Staat und erst recht den Nationalstaat ergab sich daraus das Paradox, einerseits auf Unbedingtheit und Transzendenz zu verzichten, andererseits aber für sein politisches Personal weiterhin den Eid, oft sogar mit religiösen Formeln, in Anspruch zu nehmen. Diese Tendenz zur Säkularisierung des Staates galt selbst dort, wo Politiker vom „christlichen Staat" sprachen. Der Aufgabenzuwachs des Staates und die Durchdringung der Gesellschaft mit Steuern, Wehrpflicht und Schule steigerten seine Anforderungen an die Loyalität seines Personals. Der "christliche Staat ${ }^{\text {c }}$ oder auch die „sittlich-religiöse Lebensführung“, die im Zentrum der neuen Lehrpläne für die Schulen standen, waren traditionelle Formen der Loyalitätssicherung. Dies war aber zu einer Minderheitenposition geworden ${ }^{26}$ Konservative freilich, die tatsächlich an höchsten religiösen Werten oberhalb des Staates festhielten, übten vor allem Staatskritik. Ihr prima vista liberal anmutendes Stichwort lautete "Vielregierereic ${ }^{\text {c. }}{ }^{27}$

Pre-Eminence or Authority, Ecclesiastical or Spiritual within this realm“. Vgl. Ernst Friesenhahn, Der politische Eid, Bonn 1979, 20.

22 Vgl. Prodi, Das Sakrament der Herrschaft.

23 Vgl. Holenstein, Seelenheil und Untertanenpflicht, 61.

24 Vgl. Dieter Hüning, „Unrechtmäßiger Geisteszwang oder zulässiges Erpressungsmittel der Wahrheit? Die Rolle des Eides in Kants Rechtslehre", in Peter Friedrich et. al (Hrsg.), Fatale Sprachen. Eid und Fluch in Literatur-und Rechtsgeschichte, München 2009; Marcus Twellmann, ,Über die Eide: Zucht und Kritik im Preußen der Aufklärung, Konstanz 2010.

25 Vgl. Friedrich Wilhelm Graf, „Die Nation - von Gott erfunden, Kritische Notizen zum Theologiebedarf der historischen Nationalismusforschung", in Gerd Krumeich et. al. (Hrsg.), , Gott mit uns . Nation, Religion und Gewalt im 19. und frühen 20. Jahrhundert, Göttingen 2000, 298.

26 Zur Bedeutung der religiös-sittlichen Lebensführung in den Lehrplänen vgl. Siegfried Weichlein, Nation und Region. Integrationsprozesse im Bismarckreich, Düsseldorf 2006, 333ff.

27 Vgl. Siegfried Weichlein, Nationsbilder und Staatskritik im deutschen Katholizismus des 19. und 20. Jahrhunderts, in Urs Altermatt/Franziska Metzger (Hrsg.), Religion und Nation. Katholizismen 
Die Kritik am konfessionellen politischen Eid rührte vom säkularen Staat und dem Bestreben der Liberalen nach einer Trennung von Kirche und Staat her. Bereits die Forderung nach einem Nationalstaat bedeutete eine massive Säkularisierung der politischen Ordnung. Die Bindung von Staatlichkeit an den Konfessionsgedanken war spätestens mit der napoleonischen Territorialrevolution obsolet geworden. Zudem hatte die Französische Revolution massiv die Trennung von Staat und Kirche vorangetrieben. Jeichzeitig wollten aber auch die Spitzen der monarchisch-bürokratischen Staaten wech 1815, die Konstitutionellen und die Nationalbewegten, nicht auf die Selbstverptichtung ihrer Bürger verzichten, vor allem dann nicht, wenn sie ein politisches Amt tentraten. Im Konstitutionalismus legten hiervon Verfassungseide, Beamteneide und Eahneneide Zeugnis ab. ${ }^{28}$ Beides, Eidkritik und Eidbedarf, schlugen sich in der Publizzstik über den Eid nieder, die zu Beginn des 19. Jahrhunderts sprunghaft zunahm. ${ }^{29}$

Für die Vertreter des modernen Konstitutionalismus stellte sich ein weiteres Protem. Konfessionelle Eidesformeln waren nicht mit der Glaubens-, Gewissens- und Reżonsfreiheit vereinbar, die sich immer häufiger in den Verfassungen wiederfanden. ${ }^{30}$ Eegen den Zwang, sich einer der beiden Eidesformeln zu bedienen, protestierten unter Berufung auf die Religions- und Gewissensfreiheit Dissidenten, religiöse Sekten und DLJen. ${ }^{31}$ Auch Atheisten sahen sich diskriminiert. Sie wollten überhaupt keinen Eid zolegen. Andere erklärten sich im Prinzip bereit, den Eid zu leisten. Sie konnten sich Ė̃ach unter den religiösen Formeln nichts vorstellen. Ein Staat, der die Gewissen seiच: Bürger für „Amt und Würden“ in Pflicht nahm, konnte damit jedoch schlecht kosistieren.

Die beiden Knotenpunkte, an denen diese Fragen diskutiert wurden, waren die 7 tunskirchendebatten 1848 um das Verhältnis von Staat und Kirche, um Religionsfreiz:ث: und den politischen Eid und die Reichstagsdebatte um die Zivilprozessordnung 1776 , die um den Gerichtseid kreiste. 1848 bestimmte die Frage der Religionsfreiheit

W Europa des 19. und 20. Jahrhunderts, Stuttgart 2007, 145; Verhandlungen Bayerischer Landtag 9.1.1878, 194 (Rittler).

Fl. dazu Friesenhahn, Der politische Eid.

Th. u.: Friedrich Bayer, Betrachtungen über den Eid. Enthaltend eine ausführliche Erörterung Zacke-Volmerstein, Der Eid: eine religiöse Abhandlung, Barmen 1830; Johann H. C. Nonne, Eid rivd Meineid: zwei Predigten, Schwelm 1833; F. A. Habbe, Der Eid als offentliche Religionshandrogg oder Sakrament, Berlin 1835; E. C. A. von Görtz, Über den Eid in religiöser und politischer Whsicht sowie über den jetzt herrschenden Missbrauch in den Gerichten, Quedlinburg 1836; Jozana Josef Süss, Der Eid in seiner Würde und Heiligkeit, Lennep 1836; Karl Friedrich Göschel, $Z \geqslant$ Eid nach seinen Principe, Begriffe und Gebrauche, Berlin 1837; Friedrich Gottfried Leue, Von It) Natur des Eides. Eine Abhandlung, Aachen 1836.

.... Martin Borowski, Die Glaubens- und Gewissensfreiheit des Grundgesetzes, Tübingen 2006; E- - - $\mathrm{st-Rudolf} \mathrm{Huber,} \mathrm{Deutsche} \mathrm{Verfassungsgeschichte} \mathrm{seit} \mathrm{1789,} \mathrm{Bd.} \mathrm{2,} \mathrm{Stuttgart} 1960$.

Zza jüdischen Protest gegen konfessionellen Eideszwang vgl. Andreas Gotzmann, Jüdisches Recht Tralturellen Prozess, Tübingen 1997, 273f; Zacharias Frankel, Die Eidesleistung der Juden in -soñogischer und historischer Beziehung, Dresden 1840; Leopold Zunz, Die Vorschriften über die Ejesleistung der Juden, Berlin 1859. 
die Debatte um die Neuordnung des politischen Eides. ${ }^{32}$ In den Verfassungsberatunge: von 1848 etablierte sich ein Muster, das bis ins 20. Jahrhundert hinein die Debatten ure den Eid strukturierte. Die Verbindung der Religions- und Gewissensfreiheit mit derest politischen Eid wurde nämlich über die Reform der Eidesformeln, nicht des Eides als solchem ausgetragen. Wer 1848 Staat und Kirche trennen wollte, wer die Religionsfre:heit sichern wollte, tat dies durch Um- und Neuformulierungen der konfessionellen oder religiösen Formeln. Bezeichnend war die Haltung der Paulskirchen-Linken, die des Staat von den religiösen Eidesformeln unabhängig machen wollte, am Eid als solchem aber festhielt. Mehrere Abgeordnete forderten, es dürfe staatlicherseits keinen Zwang „Zu einer religiösen oder kirchlichen Handlung“ oder zu ,irgendwelchen religiösen Pflichten" geben. Die Lösung für die Aufgabe, den staatlichen Eid und die konfessionellen Eidesformeln miteinander zu vermitteln, fanden die Frankfurter Abgeordneten im allgemeinen religiösen Eid, der die vielen konfessionellen Eidesformeln abschaffen sollte.

Für den Leipziger Abgeordneten Karl Biedermann gehörte der Eid nur dem Staat und war ein ausschließlich, juristisches und politisches Moment ${ }^{\text {c }}{ }^{33}$ Am 22. August 1848 forderte er in Frankfurt die ,strenge Durchführung des Prinzips der Trennung von Kirche und Staat" ${ }^{* 34}$ Dem Staat müsse alles das zurückgegeben werden, was er bisher entweder ganz der Kirche überlassen, oder nur in Gemeinschaft mit der Kirche besessen habe. Neben der Ehe und der Kontrolle über die Geburten durch die allgemeine Einführung der Zivilstandsregister gehörte dazu vor allem ,der Eid in seiner bürgerlichen Bedeutung, der Eid als juristisches und politisches Moment, losgetrennt von der religiösen Beziehung, die man doch hauptsächlich nur aus äußerlichen Rücksichten, wenigstens in neuerer Zeit, noch damit verbunden hat, und die bei einer tieferen Anschauung der Sache durchaus nicht notwendig dazugehört, die wegfallen muss, wenn man das Prinzip rein durchführen will $1^{6 .}{ }^{35}$ Biedermann war die markanteste Stimme unter denjenigen, die sich für die Säkularisierung des Eides und seine restlose Verstaatlichung einsetzten. Übrig bleiben sollte ein rein bürgerlicher, juristischer und politischer Eid, dem keinerlei Form von Religion mehr anhaftete. Biedermann konnte sich damit noch nicht einmal auf der politischen Linken durchsetzen. Die Mehrheit seiner Gesinnungsgenossen und erst recht der Nationalversammlung wollte am politischen Eid mit einer allgemeinen religiösen Formel festhalten. Das schloss freilich nicht aus, dass man Minderheiten wie die Mennoniten anders behandeln wollte. Die Kompromisslinie zwischen der radikalen Trennung von Staat und Kirche und dem Beibehalten des Eides war der Beschluss der Nationalversammlung: „Die Form des Eides soll eine für alle gleichmäßige, an kein bestimmtes Religionsbekenntnis geknüpfte sein. ${ }^{636}$

32 Vgl. Stenografische Berichte der Nationalversammlung von 1848, Bd. 3, hrsg. v. Franz Wigard, $696,1644,1752,1763,2012,4134$.

33 Stenografische Berichte 1848, Bd. 3, 1644.

${ }^{34}$ Ebd.

35 Ebd.

${ }^{36}$ Zit. in: Eduard Hubrich, Konfessioneller Eid oder religionslose Beteuerung, Rechtshistorisch und rechtsdogmatisch beleuchtet, Leipzig 1899, 122. Noch deutlicher brachte diese Intention der Minorität der Antrag zur Geltung: „Die Form des Eides soll eine für alle gleichmäßige, an kein bestimm- 
Das Ergebnis war eine Vereinheitlichung der religiösen Eidesformeln: Politische Eide endeten gemäß der Frankfurter Verfassung mit der Formel ,so wahr mir Gott helfe!"“ Das galt auch für den Eid des deutschen Kaisers, den die Paulskirche 1849 in Artikel 190 beschloss. Er lautete: ,Ich schwöre, das Reich und die Rechte des deutschen Volkes zu schirmen, die Reichsverfassung aufrecht zu erhalten und sie gewissenhaft zu vollziehen. So wahr mir Gott helfe." Die religiöse Schlussformel „so wahr mir Gott helfe“" sollte die bis dato üblichen konfessionellen Formeln ersetzen. Zwar war diese Formel auch bisher schon gebraucht worden. Aber der Zusammenhang hatte jedes Mal erkennen lassen, dass mit dieser Formulierung ein spezifisch christliches Gottesverständnis gemeint gewesen war. Die Frankfurter Paulskirche wollte hierüber hinausgehen. Sie knüpfte mit ihrer Formulierung an die vernünftige Gotteserkenntnis des Deismus aus dem 18. Jahrhundert an. In Frankreich hatte die allgemein deistische Richtung bereits am Ende des 18. Jahrhunderts in der Säkularisierung des Eides eine zentrale Rolle gespielt. Auch in Frankfurt vertraten zahlreiche Abgeordnete diesen Standpunkt. Der Abgeordnete Wilhelm Zimmermann meinte: „Die freie Kirche wird übergehen in eine Religion des Geistes. ${ }^{\text {‘37 }}$ Der Abgeordnete Friedrich Theodor Vischer sekundierte, die Religion müsse von der Kirche befreit werden. „Dann wird man die Kirche suchen und die Religion finden. Die reine, menschliche, sittliche Religion, die politische, die mit dem Staat eins sein muss und eins sein kann ohne Gefahr, weil sie keinen Dogmenzwang mehr kennt. ${ }^{{ }^{c} 38}$ Die Forderung nach dem konfessionsfreien staatlichen Eid stand letztlich für mehr. Sie zielte auf die Verstaatlichung sämtlicher res mixtae, also auch auf die Ersetzung der religiös geschlossenen Ehe durch die Zivilehe und auf die Einrichtung von Zivilstandsregistern.

Auch wenn die Frankfurter Paulskirchenverfassung nie in Kraft trat, so adoptierten die einzelnen Bundesstaaten doch im Gefolge diese allgemein-religiöse Eidesformel. Sogar das gegenrevolutionäre Österreich übernahm die Wendung ,so wahr mir Gott helfe" mit der Strafprozessordnung vom 17. Januar 1850 für den assertorischen Eid. In Bayern geschah dies am 10. November 1848. In Preußen legte die Verordnung vom 6. Mai 1867 für den Beamteneid die Formulierung fest: „Ich N. N. schwöre zu Gott dem Allmächtigen und Allwissenden, daß Seiner Königlichen Majestät von Preußen, meinem Allergnädigsten Herm, ich untertänig, treu und gehorsam sein und mir alle vermöge meines Amtes obliegenden Pflichten nach meinem besten Wissen und Gewissen genau erfüllen, auch die Verfassung gewissenhaft beobachten will, so wahr mir Gott helfe." 39

Die Liberalen modernisierten 1876 das Gerichtswesen und etablierten gegen den heftigen Widerstand der Zentrumspartei und konservativer Protestanten den nicht-konfessionellen Eid. Ergebnis der Beratungen der Ausschüsse und des Plenums war die Formulierung: „Ich schwöre bei Gott dem Allmächtigen und Allwissenden [...] so wahr

tes Religionsbekenntnis geknüpfte, aber mit der allgemeinen Berufung auf die Gottheit verbundene sein" (ebd.).

37 Stenographische Berichte 1848, Bd. 3, $2176 \mathrm{f}$.

38 Ebd., 1703.

${ }^{39}$ Friesenhahn, Der politische Eid, 84. 
mir Gott helfe." Sie trat am 1. Oktober 1879 in Kraft. ${ }^{40}$ Damit war für alle diejenigen Schwörenden, die nicht kirchlich gebunden waren, eine generelle Eidesformel gefunden. Auch Atheisten mussten mit der allgemeinen religiösen Formel schwören. Noch in einer anderen Hinsicht entkonfessionalisierte das liberale Zeitalter den politischen Eid. 1869 ersetzte ein preußisches Gesetz das Schwören mit den erhobenen drei Schwurfingern, die für die Trinität standen, durch das Erheben der rechten Hand, das als allgemein-religiöses Symbol nicht mehr christlich verstanden werden musste. Damit lag der Wandel des politischen Eides in Deutsch́land im Trend der westeuropäischen Entwicklung. Die deutsche Schlussformel von 1848 bzw. 1876 war auch in Belgien gebräuchlich. ${ }^{41}$

\section{Die Rekonfessionalisierung der Eidesformeln}

Der Homogenisierung des politischen Eides auf dem Höhepunkt der liberalen inneren Reichsgründung folgte eine Phase der Fragmentierung und der Ausnahmeregelungen, in welcher der Reichstag konfessionelle Eide wieder akzeptierte. Tatsächlich war der Gerichtseid in der Zivilprozessordnung von 1876 auf halbem Wege zu einer allgemeinreligiösen Formel stehen geblieben. Sie eignete sich nach den Motiven der Gesetzesvorlage "für die Mitglieder aller Religionsparteien, welchen der Monotheismus als die Grundlage des Glaubens gilt" ${ }^{42}$ Tatsächlich aber schien dies eher für die Schlussformel „so wahr mir Gott helfe " $\mathrm{zu}$ gelten. Der hier gemeinte Gott ließ „als letzte Ursache aller Dinge [...] für die vorhandenen Gegensätze der religiösen und philosophischen Anschauungen (den) weiteste(n) Spielraum". ${ }^{43}$ Dagegen sanktionierten die Eingangsworte „bei Gott dem Allmächtigen und Allwissenden“ die christlich-monotheistische Sicht. ${ }^{44}$ Auch die Zivilprozessordnung hatte noch nicht eindeutig und verbindlich das Verhältnis von Religion und Politik im Amtseid festgelegt. Dennoch hielten aber alle an der Debatte Beteiligten an der Homogenisierung der Eide schon aus religiösen Gründen fest. Im gesamten Reich sollte nur eine einzige Regelung der Eidesformeln gelten. Wäre der Gebrauch der Eidesformeln ganz oder teilweise freigestellt, so würde diese Willkür der Heiligkeit des Eides widersprechen. ${ }^{45}$

1880 erlaubte ein königlicher Erlass in Preußen wieder konfessionelle Eidzusätze, was das Reichsgericht 1884 bestätigte. Petitionen von konservativen Abgeordneten und Antisemiten forderten dagegen, generell die konfessionellen Eidesformeln wieder gesetzlich zu machen. 1897 beschäftigte sich der Reichstag damit ausführlich. Im Jahr

40 Über die Entstehung der reichsgesetzlichen Formel: Hubrich, Konfessioneller Eid oder religionslose Beteuerung, 62.

41 Vgl. Herbert Teutsch, Die Entwicklung der Theorie einer nichtreligiösen Eidesformel unter Berücksichtigung des philosophischen, theologischen und juristischen Schriftums und der Gesetzgebungsmaterialien, Köln 1966, 122.

42 Hubrich, Konfessioneller Eid oder religionslose Beteuerting, 158.

43 Ebd.

44 Ebd.

45 Vgl. ebd., 167. 
darauf erlaubte die Militärstrafgerichtsordnung konfessionelle Eidzusätze. ${ }^{46}$ Die Rekonfessionalisierung des Eides führte in einen Schwebezustand, in dem auf dem Boden einer allgemein-religiösen Formel konfessionelle Eidesformeln wieder anerkannt wurden. Bei der kaiserlichen Marine wurden sie ab 1911 sogar wieder verbindlich gemacht.

Für Juden galten diese Zusammenhänge dagegen nicht oder nur eingeschränkt. ${ }^{47}$ Sie hatten überhaupt die weiteste Strecke zurückzulegen, um öffentliche Ämter übernehmen zu können. Ihr Eidzeremoniell - wie das lange übliche Sitzen auf einem Sarg, ein blankes Schächtmesser in der Hand - spiegelte mehr die religiöse Stigmatisierung von außen als ihr eigenes religiöses Selbstverständnis. Bis 1861 galten für Juden besondere Eidesvorschriften. ${ }^{48}$ Sie hatten in der Synagoge in Gegenwart zweier Zeugen oder eines jüdischen Assessors zu schwören, sich die Hände zu waschen, den Gebetsmantel und die Gebetsschnur anzulegen und die bekleidete Thora im Arm zu tragen. Juden schlossen den Eid mit „bei Adonai, dem Gotte Israels“, einer Formulierung, die im zeitgenössischen Judentum ungebräuchlich war. Juden erwarteten sich vom Nationalstaat eine Emanzipation von diesen diskriminierenden Eidesformen. Nach Petitionen aus Berlin und Magdeburg ${ }^{49}$ wurde in Preußen 1869 die Eidesformel für Juden vereinfacht als: „Ich schwöre bei Gott dem Allmächtigen und Allwissenden [...] so wahr mir Gott helfe!" und alle abweichenden Vorschriften aufgehoben. Eben diese Formulierung wurde aus völlig anderen Gründen in den Justizgesetzen von 1876 für alle Reichsangehörigen werbindlich gemacht. ${ }^{50}$ Es blieb den Antisemiten vorbehalten, den bürgerlichen Eid als zwangsweise Übernahme des Judeneides als antijüdisch zu diffamieren. Der antisemitische Abgeordnete Liebermann von Sonnenberg nannte den Eid der Justizgesetze von ${ }_{1878} 87$,Judeneid“, ${ }^{51}$ was fortan ein antisemitischer Topos wurde, genauso wie die Absehnung konfessioneller Eide vor jüdischen Richtern oder Staatsanwälten. Der gefeiertste Redner der Antisemiten, Hermann Ahlwardt, zog mit seiner antisemitischen

- Thomas Vormbaum, Der Judeneid im 19. Jahrhundert, vornehmlich in Preußen, ein Beitrag zur juristischen Zeitgeschichte, Berlin 2006, 211. Es hanðelte sich um $\S 42$, Nr. 3 der Militärstrafgerichtsordnung von 1898.

- Dem jüdischen Zeugen Moritz Meyer aus Halberstadt wurde es 1898 nicht erlaubt, während der Eidesleistung nach jüdischer Sitte die Kopfbedeckung aufzubehalten. Vgl. Vormbaum, Der Judeneid, 206f.

Vgl. Frankel, Die Eidleistung der Juden.

Petitionen aus Berlin (400 Synagogengemeinden, 3.4.1850), aus Magdeburg (172 Synagogengemeinden, 1.3.1859) und wieder aus Berlin (379 Synagogengemeinden, 12.4.1860) -sprachen sich dahin aus, dass die gegenwärtigen Formen des Judeneides dem religiösen Bewusstsein der Juden nicht mehr genehm seien." Stenographische Berichte des Reichstages des Norddeutzshen Bundes 1868, Aktenstück Nr. 89, Dritter Bericht der Petitionskommission.

7 gl. Vormbaum, Der Judeneid.

Zit. in: Hermann Strathmann, „Ist der gesetzliche Eid noch haltbar? Eine politisch-theologische - Untersuchung", in Theologische Fakultät Erlangen (Hrsg.), Festgabe für Theodor Zahn, Leipzig 928,74 . 
Eidpolemik durchs Land und warf dem bekannten Bankier Gerson von Bleichröder vor, falsche Eide geleistet zu haben. ${ }^{52}$

Obwohl diese Fälle assertorische Gerichtseide waren, wurde die politische Debatte prinzipiell und betraf auch den promissorischen politischen Eid. Bereits 1883 forderte der konservative Abgeordnete Maltzahn-Gültz, dass religiöse Eide nur von Religionsgenossen abgenommen werden sollten. ${ }^{53}$ Dieser Antrag wurde zwar vom Reichstag nicht verhandelt, fand jedoch Zustimmung in der evangelischen Kirche. Die preußische Generalsynode sah 1894 in der Vereidigung eines Christen durch einen Nicht-Christen einen „Notstand“, dern unbedingt abgeholfen werden müsse. ${ }^{54}$ Der Antisemitismus höhlte die Substanz des Amtsgedankens, mithin die Trennung zwischen der Person und der personenungebundenen Ämterstruktur, bereits früh aus. ${ }^{55}$

\section{Der politische Eid in der Weimarer Republik}

Die Weimarer Nationalversammlung blieb 1919 bei der Neuordnung der Eide in den Bahnen der Diskussion seit 1848. Überhaupt dominierte die Frage der Eidesformel in der gesamten Debatte um den Eid zwischen 1848 und 1919. Prämisse der Neuordnung von 1919 sollte es sein, dass der Zwang zur bisherigen Schwurformel im neutralen Staat und unter den Bedingungen einer vollen Gewissensfreiheit nicht mehr möglich war. Die bisherige Schwurformel galt als nicht mehr zeitgemäß.

Wer jedoch erwartet hatte, dass die vor 1914 heiß umstrittene Eidesfrage in der Nationalversammlung einen großen Raum einnehmen würde, sah sich getäuscht. Die Mütter und Väter der Weimarer Verfassung behandelten die Eidesfrage übereinstimmend und geräuschlos nicht als Frage des politischen Eides, sondern als Teil der beabsichtigten Trennung von Staat und Kirche. Sie griffen damit Intentionen aus der Frankfurter Nationalversammlung von 1848 wieder auf. ${ }^{56}$ Die Trennung von Staat und Kirche erforderte, dass niemand durch den Staat zu irgendeiner religiösen Handlung oder religiösen Eidesleistung gezwungen werden durfte, eine Forderung, der sich Linksliberale und auch Zentrumsabgeordnete anschließen konnten. Die Weimarer Verfassung folgte in Artikel 136,4 einer revolutionären Forderung des Rates der Volksbeauftragten vom 12. November 1918: „Niemand darf zu einer kirchlichen Handlung oder Feierlichkeit oder zur Teilnahme an religiösen Übungen oder zur Benutzung einer religiösen Eidesformel gezwungen werden. ${ }^{457}$ Daraus ergab sich dann die religionslose Eidesformel. Sie lau-

52 Vgl. Vonnbaum, Der Judeneid, 201; Hermann Ahlwardt, Der Verzweiflungskampf der arischen Völker mit dem Judentum. II. Teil: Der Eid eines Juden, Berlin 1890.

53

(t) Ist gesetzliche Eid noch haltbar?, 77

54 Hubrich, Konfessioneller Eid oder religionslose Beteuerung, 133; Carl Kade, Der Eid und das Recht auf Wahrheit, Berlin 1895, 13f; Strathmann, Ist der gesetzliche Eid noch haltbar?, 76.

55 Vg1. Stenographische Berichte des Reichstages des Deutschen Reiches, 204. Sitzung, 2.4.1897, 5454ff.

56 Vgl. den Eid der Frankfurter Paulskirchenverfassung: „Ich schwöre, die Reichsverfassung getreulich zu beachten und mit allen Kräften aufrechtzuerhalten."

57 Aufruf des Rats der Volksbeauftragten vom 12.11.1918, Ziffer 5. 
tete für den Reichspräsidenten: „Ich schwöre“, fakultativ konnte der allgemein religiöse Zusatz „so wahr mir Gott helfe" hinzugefügt werden. ${ }^{58}$ Artikel 177 WRV ersetzte alle abweichenden Reglungen in der Gesetzgebung durch die nicht-religiöse Eidesformel „Ich schwöre“, wobei allgemein-religiöse Zusätze zulässig blieben: ${ }^{59}$ "Wo in den bestehenden Gesetzen die Eidesleistung unter Benutzung einer religiösen Eidesform vorgesehen ist, kann die Eidesleistung rechtswirksam auch in der Weise erfolgen, dass der Schwörende unter Weglassung der religiösen Eidesform erklärt: ,ich schwöre““.

Während der politische Eid im Kaiserreich ein auch von Staats wegen gewollter religiöser Vorgang (,,christlicher Staat") war, der durch allerhand konfessionelle Ausnahmeregelungen relativiert wurde, versuchten die Abgeordneten der Nationalversammlung ihn seiner religiösen Bedeutung zu entkleiden und ihm eine religionslose Form $\mathrm{zu}$ geben. Die Eidesordnung war gegenüber dem Kaiserreich umgekehrt worden: Religion war nicht mehr die Norm, sondern die Ausnahme. ${ }^{60}$ So dachten zumindest die Abgeordneten in Weimar, die überzeugt waren, den Eid säkularisiert zu haben. ${ }^{61}$

Die Weimarer Republik erreichte damit gewissermaßen den westeuropäischen Normalstandard in Fragen der Eidesleistung. Ihre Eidesbestimmungen hatten eine Reihe von Vorbildern in Westeuropa, wo seit längerem der religionslose Eid durch das einfache Schwören sichergestellt war. So wurde in England 1888 der konfessionelle Eid abgeschaff, in Italien 1877. Die schweizerische und englische Gesetzgebung erlaubten denjenigen, die eine konfessionelle Eidesformel ablehnten, auf „Ehre und Gewissen“ zu schwören. In Italien genügte durch das Gesetz vom 30. Juni 1876, das dem französischen Vorbild folgte, der einfache Ausdruck „giuro / ich schwöre“ mit der gleichen Rechtsverbindlichkeit.

\section{Eid und Performanz}

Zur religiösen Spezifik des Eides gehörte noch etwas anderes. Das Schwören selbst war ein performativer religiöser Akt. Dafür sind bisher mehrere und widersprüchliche Begründungen angegeben worden. Einerseits liegt die Performanz in einem magischen Verständnis des Eides begründet. Durch den Gẹrauch der Worte „Eid“ und ,ich schwöre“ bindet der Eidleistende „die Gottheit und sich selbst in einen Zwangszusam-

58 Vgl. Teutsch, Die Entwicklung der Theorie einer nichtreligiösen Eidesformel.

59 Die weitergehende Trennungsabsicht für Staat und Religion, die der Mehrheitssozialdemokrat Johannes Meerfeld in der Sitzung des Verfassungsausschusses verfolgte, nämlich generell auf den Eid zu verzichten und auf andere Beteuerungsformeln zurückzugreifen, fand dagegen keine Mehrheit. Zur Rolle Meerfelds in den Debatten über Staat und Kirche in der Weimarer Nationalversammlung vgl. Siegfried Weichlein, „Von der Staatskirche zur religiösen Kultur. Die Entstehung des Begriffs der ,Körperschaft öffentlichen Rechts“ mit Blick auf die Kirchenartikel der Weimarer Reichsverfassung ', in Lucian Hölscher (Hrsg.), Baupläne der sichtbaren Kirche, Göttingen 2007.

60 Vgl. Friedrich Giese, Grundzïge des katholischen Kirchenrechts und des Staatskirchenrechts, Köln 1932, 291.

1 Vgl. Strathmann, Ist der gesetzliche Eid noch haltbar?, 4. 
menhang zwischen seinem Tun und der auf sein Haupt herabbeschworenen göttliche: Rache". Wie im Begriff der „bedingten Selbstverfluchung" ausgedrückt, stellt der Eitleistende , in Form magischer Beschwörung die göttliche Rache in den Dienst mense licher Interessen". ${ }^{62}$ Das ,ich schwöre" geschieht öffentlich. Die Anrufung eines Dritze: beim Schwören erhöht die Bindungskraft des Schwurs für den Eidleistenden. Ds Schwören stellt eine trianguläre Beziehung zwischen dem Eidleistenden, dem Eidne:mer und dem Eideshort dar. Das unterscheidet das Schwören von anderen Formen des Versprechens. Indem Eide eine trianguläre Beziehung $\mathrm{zu}$ einem imaginierten Dritter herstellen, produzieren sie etwas Neues. Sie sind performativ.

Andererseits erinnern einige Autoren daran, dass typischerweise bei einem Name geschworen wird und daher mindestens eine weitere Dimension zentral ist. Beim EL ging es - so Giorgio Agamben im Anschluss an frühe strukturalistische Theoretiker wite Émile Benveniste und George Dumézil - „ursprünglich nicht allein um die Garanz: eines Versprechens oder um die Wahrhaftigkeit einer Behauptung“. Der Eid konservie: vielmehr die Erinnerung an ein archaischeres Stadium, „in dem sich der Eid auf cie Konsistenz der menschlichen Sprazhe selbst sowie der Natur der Menschen als, spz chende Wesen' bezog“. Der Eid heilte damit nicht nur die Unfähigkeit, die Wahrheit z. sagen, sondern mindestens genauso sehr „eine der Sprache selbst inhärente Gebrec: lichkeit, eine Infragestellung des Vermögens der Worte, sich auf die Dinge selbst It beziehen, wie der Fähigkeit der Menschen, sich selbst in ihrer conditio als sprechende Wesen zu erkennen." ${ }^{63}$

Zum offentlichen Thema wurde die performative Seite des Eides weniger durch dis Eidesdebatten, sondern vielmehr durch die Debatte um den Meineid. Insbesondere nas: 1890 häuften sich Stimmen, die um den religiösen Wert des Eides als solchem besorg waren und ihn durch Meineide und die Eidpraxis profaniert sahen. Ihre bis ins Hockspekulative reichende Sorge galt vordergründig der Reinheit und Heiligkeit des Eices als solchem. Aus Fällen von Meineid folgerten sie auf die mangelnde Beobachtung det Heiligkeit des Eides und darüber hinaus - was dem Ganzen einen politischen Charakte: verleiht - auf mangelnde Sittlichkeit. Derartige Debatten bezogen sich in erster Liniz auf assertorische Gerichtseide und deren religiöse Performanz. Sie fanden vornehmlic: in Strafrechtskommissionen und den evangelisch-sozialen Kongressen statt. ${ }^{64}$

Im späten Kaiserreich dramatisierten Autoren verschiedener politischer Provenienz die „Eidesnot" und das "dauernde Zunehmen des Meineides". Schlagwörter wie „Meineidsseuche"

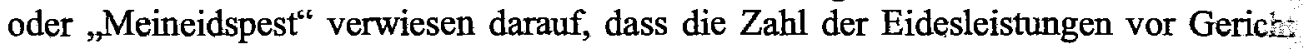

62 Helmut Gollwitzer, „Einführung“, in Hildburg Bethke, Eid, Gewissen, Treuepflicht, mit einer Eiführung von Helmut Gollwitzer, Frankfurt a.M. 1965, 7.

63 Agamben, Das Sakrament der Sprache, 12, 14.

64 Vgl. Vormbaum, Eid, Meineid und Falschaussage. Reformdiskussion und Gesetzgebung seit 187 Berlin 1990; vgl. u.a. Franz von Liszt, Meineid und falsches Zeugnis: eine strafrechtgeschichtliche Studie, Wien 1876; Heinrich Sohnrey, Der Meineid im deutschen Volksbewusstsèr: Leipzig 1894; Karl StooB, „Meineid“, in Vergleichende Darstellung des deutschen und auslän:schen Strafrechts, Besonderer Teil, Bd. III, Religionsvergehen, Falsche Anschuldigung, u.a., beats. v. Wilhelm Kahl et al., Berlin 1906. 
massiv angestiegen war, mit ibr aber auch die Zahl der Meineide. ${ }^{65}$ Die Zeugenvernehmungen hatten mit dem Ausbau des Justizsystems seit der Mitte des 19. Jahrhunderts „ungeheuer zugenommen“. Wilhelm Kahl hielt dem 1903 auf dem evangelisch-sozialen Kongress in Darmstadt zwar entgegen, die Meineidverurteilungen seien seit zwanzig Jahren stetig gefallen. 1882 hatte es noch 1011 Verurteilungen wegen Meineids gegeben, 1902 nur noch $761 .^{66}$ Doch eine Untersuchung von Staatsanwaltschaftsrat Dr. Kloß aus Halle kam 1905 auf 80.000 bis 90.000 Meineide pro Jahr im Deutschen Reich, die nur eben nicht verurteilt wurden und deshalb in den Statistiken nicht auftauchten. Seine Berechnungsgrundlage bildeten eigene Erfahrungen im Landgerichtsbezirk Halle. ${ }^{67}$ Damit trat der Eid als soziale und kulturelle Praxis und als illokutionärer Akt ins Zentrum der Debatte.

Beispiele dafür bot der Gerichtsalltag en masse. Im Kriminalgerichtsgebäude in Berlin-Moabit war man 1896 zwecks Zeitersparnis dazu übergegangen, statt die Eidesformel vom Richter vor- und vom Zeugen nachsprechen, sie von einem am Zeugentisch befestigten Plakat ablesen zu lassen ${ }^{68}$ Die Praxis der Gerichte wies dem Eid einen ganz technischen Ort zu, der sich markant von seinem illokutionären Gehalt unterschied. Das Herausgehobene des Eides und seine Konsekrationswirkung traten in den Hintergrund gegenüber den Imperativen des Gerichtsalltags, in immer kürzerer Zeit zu immer mehr Urteilen zu kommen. Die Praxis der Gerichtseide bestätigt Max Webers Beobachtung, dass sich die Gerichte zu Paragraphenautomaten entwickelt hätten. ${ }^{69}$ Zahlreiche Stimmen nahmen dies als Profanierung des Eides wahr und protestierten gegen die Rationalisierung einer die Ratio bindenden und ihr übergeordneten Instanz. Die religiöse Aura des Eides und der Massenbetrieb bei Gerichtseiden standen mehr und mehr in Widerspruch zueinander.

Die Kehrseite der gesetzlich verankerten religiösen Eidesformel war, dass die Meineide anstiegen, was wiederum als Indiz für „,besondere Irreligiosität“ und „Volksverwilderung " interpretiert wurde - besonders in den evangelischen Kirchensynoden. Aber auch der Berliner Pädagoge und Pbilosophieprofessor Friedrich Paulsen konstatierte: „Der Eid ist eine gefährliche Waffe der äußersten Gewissenlosigkeit geworden. ${ }^{670}$ Für Franz Liszt, Strafrechtler in Berlin, war der Eid nun einmal der „Grundpfeiler des ganzen Rechtslebens“, „heute ist der Glaube an die Heiligkeit des Eides eine fable

${ }^{65} \mathrm{Vgl}$. Strathmann, Ist der gesetzliche Eid noch haltbar?, 58ff; Kade, Der Eid und das Recht auf Wahrheit; Kulemann, Die Eidesfrage, Eisenach 1904.

66 Wilhelm Kahl, „Die Reform des deutschen Strafrechts im Lichte der evangelischen Sozialethik“, in Verhandlungsbericht des Evangelisch-sozialen Kongresses 1903 in Darmstadt, Göttingen 1903.

Kloß kam auf 812 Zeugenvernehmungen, von denen er 6 als Meineide qualifizierte. Diese Zahlen rechnete er dann hoch auf die Gesamtzahl aller Prozesse. Vgl. Alfred Kloß, „Der Meineid in Strafsachen, seine Häufigkeit und verhältnismäßig seltene Bestrafung, Vorschläge und Abhilfe", in Zeitschrift für Kriminalpsychologie, 3, 1906 sowie Ders., in Jahrbuch der Gefängnisgesellschaft für die Provinz Sachsen und das Herzagtum Anhalt, 21, 1905, zit. in Hermann Strathmann, Ist der gesetzliche Eid noch haltbar?, 6.

$68 \mathrm{Vgl}$. Strathmann, Ist der gesetzliche Eid noch haltbar?, 61.

${ }^{69}$ Max Weber, Wirtschaft und Gesellschaft. Grundriss der verstehenden Soziologie, Tübingen 1972, 826.

70 Zit.n. Strathmann, Ist der gesetzliche Eid noch haltbar?, 65. 
convenue, an die wir aus Bequemlichkeit fortglauben, genauer fortzuglauben heucheln". ${ }^{71}$ Hermann Strathmann, Jurist in Erlangen, arbeitete das Widersprüchliche an den Strafen für Meineide heraus. Der Staat komme in diesen Strafen gleichsam der Gottheit zu Hilfe, ,während die ganze Institution [des Eides; S.W.] vielmehr darauf ruht, dass die Gottheit dem Staate zu Hilfe kommen soll. "72 Das aber werde in den Meineiden gerade verneint, missbraucht und verhindert.

Seit Beginn der 1890er Jahre suchte eine förmliche Flut von Regierungsvorschlägen, Denkschriften, Kongressvorträgen und Parlamentsverhandlungen Abhilfe gegen die Profanierung des Eides in der Gerichtspraxis zu schaffen. ${ }^{73}$ Aber weil die Kirchen den politischen Willen zur religiösen Eidesformel, letztlich die Vorstellung eines Staates auf christlicher Grundlage, teilten, blieben nur moralische Appelle übrig. So richtete die Eisenacher Kirchenkonferenz 1894 an die Kirchenregierungen die Bitte, „dass mit den Mitteln der Kirche das Gewissen des Volkes nachdrücklich geschärft und der Sinn für Wahrhaftigkeit und Heiligkeit des göttlichen Namens überall geweckt und gestärkt werde ${ }^{c} .74$ Die Kommission zur Strafrechtsreform hielt 1903 an der allgemein-religiösen Eidesformel fest und verwies auf „Herkommen, Volksbewusstsein und Mehrheit und den in der Formel enthaltenen Antrieb, die Wahrheit zu sagen ${ }^{6.75}$

Bei der MSPD sah man, unterstützt von der linksliberalen DDP, in der Eidesformel „ich schwöre" dagegen einen religionslosen Eid. Vor allem die Sozialdemokraten verwiesen dazu auf die neue Eidesformel, die auf religiöse Formulierungen verzichtete und insofern dem angestrebten Ziel der Religions- und Gewissensfreiheit Genüge tat. Dennoch hielt man am Eid fest. Ernst Friesenhahn, ein Schüler von Carl Schmitt, sah darin bereits 1927, analog zu Schmitts Diktum vom „dilatorischen Formelkompromiss“ in den Staatskirchenartikeln der Weimarer Reichsverfassung, „das Bemühen, bei aller reinlichen Scheidung des Staates von der Religion die bei vielen Staatsangehörigen vorhandenen religiösen Vorstellungen, die mit dem Eide verbunden sind, für die Zwecke des Staates dienstbar zu machen." ${ }^{76}$

Doch schon die Zustimmung des Zentrums zu dieser Formulierung ließ eine ganz andere Begründung erkennen. Das Zentrum war dem Kaiserreich stärker als die Sozialdemokraten verbunden gewesen, hatte viele seiner Regierungen getragen. Katholische Beamte mit einem Eid auf die Verfassung von 1871 waren keine Seltenheit. Sich einfach zur neuen Eidesformel zu bekennen, war damit für Zentrumsabgeordnete weniger leicht als für Sozialdemokraten. Der Zentrumsabgeordnete und Münsterische Moraltheologe Joseph Mausbach versuchte eine Brücke zwischen den alten und den neuen Eiden

71 Zit. bei Kade, Der Eid und das Recht auf Wahrheit, 47; Strathmann, Ist der gesetzliche Eid noch haltbar?, 68.

72 Strathmann, Ist der gesetzliche Eid noch haltbar?, 67.

73 Vgl. Andrea Münks, Vom Parteieid zur Parteivernehmung in der Geschichte des Zivilprozesses, Köln 1992, 130f.

74 Evangelisch-lutherische Kirchenzeitung 19.1.1894, 66; Strathmann, Ist der gesetzliche Eid noch haltbar?, 64.

75 Kommission für Reform des Strafrechts Protokoll der 8. Sitzung am 20.3.1903, Bd. 1, Berlin 1905, 65.

76 Friesenhahn, Der politische Eid, 10. 
zu schlagen. Er erkannte zum einen in den neuen Regelungen die Gewähr dafür, dass von Staats wegen nicht in die innerreligiösen Dinge eingegriffen werden sollte. Wichtiger war für ihn jedoch zum anderen, dass die Worte „Eid“ und „Schwören“ als solche einen religiösen Mehrwert ganz „unabhängig von der Verbalanrufung Gottes“ besaBen. ${ }^{77}$ Mausbach konnte sich hier auf Ludwig Windthorst und August Reichensperger berufen. Beide hatten in der Debatte um den Eid in der Justizdebatte 1876 darauf hingewiesen, dass der religiöse Kern des Eides nicht in seinen konfessionellen Zusätzen liege, sondern im Wort „Schwören" selbst, das eben schon dem Sprachgebrauch nach religiös konnotiert sei. Dem hatten sich 1905 auch die Kommission zur Reform des Strafrechts sowie zahlreiche Stimmen in der Publizistik zu diesem Thema angeschlossen. Für sie gab es keinen religionslosen Eid. „Der religionslose Eid ist ein Widerspruch in sich" formulierte der Erlanger Jurist Strathmann. ${ }^{78}$ Den Eid machte nicht die Semantik religiöser Eidesformeln, sondern seine Performanz zu einer religiösen Angelegenheit.

Ludwig Windthorst hatte bereits auf dem Höhepunkt des Kulturkampfes in der Reichstagsdebatte vom 20. November 1876 über die Eidesformeln den Eid als einen religiösen Akt in sich selbst bezeichnet. Im Grunde bedurfte es also keiner zusätzlichen religiösen Eidesformel, um ihn als religiös zu qualifizieren. Dem linksliberalen Abgeordneten Carl Herz, der den nicht-religiösen Eid forderte, hielt er entgegen, dass er dann den Eid als solchen abschaffen und an seine Stelle die bürgerliche Versicherung setzen müsse: „Ich versichere bei Strafe des Zuchthauses [...] denn Jedermann, der vom Schwören spricht, setzt als selbstverständlich voraus, dass der Schwörende Gott den Allmächtigen zum Zeugen dafür anruft, dass er die Wabrheit berichtet. “79 Die religiöse Instanz Gott wäre damit in den Zeugenstand gerufen. Windthorst spiegelte damit das klassische Argument der Wiedertäufer und Mennoniten, in urchristlicher Tradition überhaupt nicht zu schwören, weil im Akt des Schwörens eine Verzweckung Gottes oder allgemeiner: des religiösen Verhältnisses geschehe.

Für eine allgemein religiöse Performanz des Schwörens auch ohne religiöse Formeln sprach nicht nur das Zeugenargument, sondern mit Giorgio Agamben auch, dass der Schwörende im Schwören seine Wahrheitșfähigkeit als Garantieinstanz einsetzt, um die Wahrheit des Beschworenen sicherzustellen. Agamben setzt sich ab von der älteren Ansicht, die das Institut des Eides der magisch-religiösen Sphäre zurechnete. „Die magisch-religiöse Sphäre geht dem Eid nicht voraus, sondern umgekehrt gerade vermag Zer Eid als ursprüngliche performative Erfahrung des Wortes die Religion zu erklären ebenso wie das Recht, das mit ihr eng verbunden ist)." Der Eid ist somit die „perforzative Erfahrung eines Wahrsprechens" ${ }^{60}{ }^{80}$ Dieses Wahrsprechen und das Ansprechen

\footnotetext{
Fgl. Joseph Mausbach, „Die Eidesform ${ }^{\text {* }}$, in Ders., Kulturfragen in der deutschen Verfassung, Mönchen-Gladbach 1920, 129.

Strathmann, Ist der gesetzliche Eid noch haltbar?, 87; Bericht der Strafrechtskommission, Bd. 1, 2905, 47, 65; Emil Sehling, Artikel „Eidesrecht", in Realenzyklopädie für protestantische Theologie und Kirche, Bd. 5, 1898; Kulemann, Die Eidesfrage, 50; Victor Jeanorot, La question du germent, Paris $1882,14 \mathrm{f}$.

Stenographische Protokolle des Deutschen Reichstages, 12. Sitzung, 20.11.1876, 234.

VI. Agamben, Das Sakrament der Sprache, 82.
} 
einer Ebene, die wahre Aussagen überhaupt erst erlaubt, ist ein Meta-Vorgang, der über die vielen einzelnen Behauptungen im Alltag hinausgeht. Das Schwören als Sprechakt ohne jedwede nachfolgende Eidesformel ist so gesehen ein religiöser, für Agamben sogar ein religions-konstituierender Akt, zumindest aber ein meta-sprachlicher Akt. ${ }^{81}$

Das „Ich schwöre" promissorischer Eide wurde noch in einer anderen Hinsicht zum Problem. Die Weimarer Reichsregierung hielt am Beamteneid fest, der in der nichtreligiösen Formulierung abzulegen war: „Ich schwöre Treue der Verfassung, Gehorsam den Gesetzen und gewissenhafte Erfüllung der Amtspflichten. ${ }^{\text {“82 }}$ Religiöse Zusätze blieben aber zulässig. Zum Problem wurde-der Eid, weil die Weimarer Reichsverfassung in Artikel 128 andererseits den Beamten die Freiheit ihrer politischen Gesinnung garantierte. ${ }^{83}$ Als der Attaché Friedrich Everling im Auswärtigen Amt am 18. September 1919 zur Vereidigung geladen wurde, weigerte er sich, diesen Eid abzulegen, weil Presseberichten $^{84}$ zufolge die Reichsregierung nicht nur die Beobachtung der Verfassung, sondern die Treue zur Verfassung verlangte. Das aber stünde - sobald gehaltvoll interpretiert - im Widerspruch zur ebenfalls garantierten politischen Gesinnungsfreiheit der Beamten, worunter der Deutschnationale Everling die Wahl antirepublikanischer Parteien verstand. Everling war daraufhin entlassen worden, sein Fall löste eine Welle politischer Stellungnahmen und schließlich eine Letztentscheidung des Reichsdisziplinarhofs vom 22. April 1921 aus. Darin wurde die von der Regierung im Beamteneid verlangte Treue zur Verfassung als ,negative Verfassungstreue ${ }^{\varsigma}$ ausgelegt, die im Wesentlichen die Beobachtung der Verfassung, nicht aber die sehr viel stärkere gesinnungsmäßige Übereinstimmung (Treue) mit ihr voraussetzte. Die Probleme, die man durch die Streichung der religiösen Eidesformel gelöst glaubte, traten beim Begriff "Treue" wieder auf. Bei aller Diskontinuität in Fragen des Staat-Kirche-Verhältnisses stand der Verfassungseid der Beamten damit in einer deutlichen Kontinuität zum Kaiserreich: Auch da hatten die preußischen Beamten Treue dem König und der Verfassung (nur) Beobachtung schwören müssen. "Ich schwöre bei Gott dem Allmächtigen und Allwissenden, dass Seiner Königlichen Majestät von Preußen, meinem Allergnädigsten Herren, ich untertänig, treu und gehorsam sein und alle mir vermöge meines Amtes obliegenden Pflichten nach meinem besten Wissen und Gewissen genau erfüllen, auch die Verfassung gewissenhaft beobachten will, so wahr mir Gott helfe." Die Beobachtung der Verfassung war noch ein Kennzeichnen der Weimarer Jahre und nicht die Treue zu ihr. Auf der Rückseite des Vereidigungsnachweises stand bis 1926 eine erklärende Stellungnahme von Reichsinnenminister David: „Durch die in der Verordnung vom 14.8.1919 festgesetzten Formen des Beamteneides werden die in der Reichs-

81 Bundespräsident Gustav Heinemann forderte 1970, den Eid ganz abzuschaffen, da er auch ohne religiöse Beteuerungsformel einen religiösen Grundcharakter habe. Im Schriftum der 1970er Jahre tauchte wiederholt die Ansicht auf, der Eid gleiche auch ohne eine religiöse Eidesformel einem Gebet. Vgl. Jochen Müller, Religion und Strafrecht - Christliche Einflüsse auf Normenbestand, Dogmatik und Argumentationsstrukturen, des deutschen Strafrechts, Berlin 2008, 209.

82 Reichsbeamteneid vom 14.8.1919.

83 So vor allem Hugo Preuß in der Weimarer Nationalversammlung am 31.7.1919, Stenographische Berichte der verfassungsgebenden Versammlung, 31.7.1919, 2122.

${ }^{84}$ So etwa: Wolffs Telegraphisches Bureau, 9.9.1919. 
verfassung, besonders in Artikel 130, gewährleisteten Rechte in keiner Weise eingeschränkt. Das eidliche Treuegelöbnis zur Verfassung enthält nur die Bedeutung, dass der Beamte sich verpflichtet, in seiner Tätigkeit als Beamter die Verfassungsbestimmungen genau zu beobachten." Der Treueid galt Personen. Die Übertragung der Treue auf eine Sache wurde zum Problem. Das Objekt des Eides, sein Inhalt, war damit problematisch geworden.

Nach 1919 wurden weniger die Eidesformeln als vielmehr der Eidvorgang als solcher politisiert. Die Relativierung des geleisteten Eides betraf auch die politische Linke. Kommunisten ironisierten und verhöhnten den Eid auf die Verfassung von Weimar. In Dortmund erschienen nach der Stadtverordnetenwahl 1924 die kommunistischen Stadtverordneten, mit roten Fausthandschuhen in der Sitzung, um die vorgeschriebene Verpflichtung durch Handschlag ins Lächerliche zu ziehen. Als der Bürgermeister sich weigerte, unter diesen Bedingungen die Einführung vorzunehmen, wurden ihm die roten Handschuhe vor die Füße geworfen. Die 20 kommunistischen Stadtverordneten in Gelsenkirchen wuschen sich nach der Verpflichtung in mitgebrachten Waschschüsseln demonstrativ die Hände, um sich von der Berührung mit den Bürgerlichen zu reinigen. Erst ein Erlass des preußischen Innenministers Carl Severing machte solchen Praktiken ein Ende: Wer sich nicht auf angemessene Weise verpflichten ließ, durfte sein Amt als Stadtverordneter nicht ausüben. ${ }^{85}$

Die Nationalsozialisten antworteten auf die Praxis der Eidesrelativierung einerseits mit einer drastischen Eidverschärfung. Überhaupt rückte - wie der Führereid von 1934 zeigte - der Eid wieder stärker ins Zentrum der Loyalitätsverpflichtung des politischen Personals. Diese Verpflichtung geschah jedoch weniger durch eine Wiedereinführung religiöser Eidesformeln. 1933 wurden zwar wieder religiöse - nicht konfessionelle Eidesformeln eingeführt. Am 11. Mai 1933 verfügte der preußische Justizminister: „Deutsche Gerichte werden in der religiösen Eidesform im Gegensatz zur weltlichen die Eidesform erblicken, die allein den sittlichen Überzeugungen des deutschen Volkes entspricht. ${ }^{486}$ Am 20. August 1934 ersetzten die Nationalsozialisten den Weimarer Loyalitätseid der Beamten auf die Verfassung durch einen persönlichen Treueid auf die Person Hitlers. „Ich schwöre: Ich werde dem Führer des Deutschen Volkes Adolf Hitler treu und gehorsam sein, die Gesetze beachten und meine Amtspflichten gewissenhaft erfüllen, so wahr mir Gott helfe." Wie wenig die Nationalsozialisten von religiösen Eidesformeln hielten, zeigte sich spätestens 1937. Im Beamtengesetz von 1937 wurden wieder nichtreligiöse Eide zugelassen: „Erklärt der Beamte, daß er Bedenken habe, den Eid in religiöser Form zu leisten, so kann er ihn ohne die Schlußworte leisten. ${ }^{487}$ Die Akzentuierung der performativen Wirkung des Eides, die sich seit der Jahrhundertwende in der Eiddebatte und nach 1919 in der Politik etabliert hatte, setzte sich damit nach 1933 fort.

Die dezidiert staatliche Vereinnahmung des Eides hatte zu diesem Zeitpunkt bereits ihre theoretischen Fürsprecher gefunden. Carl Schmitt stellte in offensichtlicher Distanz

Es Vgl. Heinrich A. Winkler, Der Schein der Normalität, Berlin 1985, 462; Beatrix Herlemann, Kommunalpolitik der KPD im Ruhrgebiet 1924 bis 1933, Wuppertal 1977, 32ff.

55 Teutsch, Die Entwicklung der Theorie einer nichtreligiösen Eidesformel, 214.

Ebd., 217; Deutsches Beamtengesetz 26.1.1937, §4, 3 . 
zur Weimarer Republik in seinem Gutachten zur Dissertation Ernst Friesenhahns fest: „Auch wenn der Eid heute im öffentlichen Leben ganz zu verschwinden scheint, wird es immer wieder notwendig werden, irgendwelche förmliche Versicherungen einer loyalen Gesinnung zu fordern, damit die freiheitlichen Einrichtungen des modernen Staates nicht dazu missbraucht werden, um seine Grundlagen zu erschüttern." ${ }^{c 88}$ Von der Eidbewirtschaftung profitierte generell der moderne Staat, nicht aber die freiheitlichen Einrichtungen. Eide waren ein Kennzeichen moderner Diktaturen. Daher überrascht es nicht, dass auch die DDR ihrer atheistischen Politik zum Trotz am verpflichtenden Charakter des Eides festhielt.

\section{Fazit und Ausblick}

1. Das Bundesverfassungsgericht erkannte am 11. April 1972 in seiner Entscheidung zur Eidesverweigerung aus Glaubehsgründen für Recht an, dass der ohne Gottesbezug geleistete Eid keinen religiösen Bezug habe. Dennoch müsse man der Gewissensfreiheit derjenigen Raum gegeben, die sich unter Berufung auf das Schwurverbot in Mt 5, 33-37 weigerten zu schwören. In diesem Urteil kamen beide Linien in der Eiddiskussion des späten 19. und 20. Jahrhunderts zusammen. Es knüpfte einerseits an den Weimarer Verfassungskonsens an, einen religionslosen Eid verbindlich zu machen, andererseits aber auch an diejenige Position, die im Schwören selbst einen (hier mit Blick auf die Bergpredigt illegitimen) religiösen Akt erkannte. Bis dahin war die politische Verortung dieser Positionen uneindeutig: sowohl Atheisten wie auch Mennoniten protestierten gegen den Eid, Weimarer Sozialdemokraten und Zentrumskatholiken - die staatstragende Elite - verteidigten den Eid ohne religiöse Wendung.

Aber schon in der Verteidigung des ,religionslosen Eides" unterschieden sich Zentrum und SPD. Während die Sozialdemokraten die Streichung religiöser Zusätze als Fortschritt feierten, zogen sich eine Reihe von Zentrumspolitikern auf die Position zurück, dass bereits das Schwören eine religiöse Handlung bedeutete. So mussten sie ihrer Klientel nicht im Einzelnen erklären, warum sie zuerst auf den Kaiser den einen und jetzt auf die Republik einen anderen Eid abzulegen hatte. Der systemische Vorteil dieser abweichenden Begründung lag auf der Hand. Der religionslose Eid der Weimarer Reichsverfassung eignete sich zur Integration und als rite de passage gleichsam zur Überbrückung der Gegensätze zwischen Kaiserreich und Republik. Wenn katholische Politiker den performativen Aspekt betonten, dann stellten sie eine Brücke für die vielen konservativen Beamten her, die es ihnen erlaubte, den einmal auf die Verfassung von 1871 und die kaiserlichen Gesetze geschworenen Eid mit dem neuen republikanischen Dienstherren zu verbinden.

Das hatte im Prinzip bereits für die Zeit zwischen 1848 und 1876 gegolten. Auch der allgemein religiöse Eid mit der Formel "so wahr mir Gott helfe" hatte im bikonfessionellen Nationalstaat mit erhöhten Loyalitätsanforderungen integrativ gewirkt. Er war für Katholiken, Protestanten und Juden anschlussfähig gewesen. Beide

88 Zit. in: Friesenhahn, Zur Problematik des politischen Eides, 3. 
Formen der Integration unterschieden sich jedoch markant. Während die allgemeinreligiöse Formel additiv integrierte, weil sie für alle monotheistischen Religionen einen Anknüpfungspunkt bot, sah dies für den religionslosen Eid von Weimar anders aus. Hier kamen verschiedene Positionen mit gegensätzlichen Begründungen für die integrative Wirkung des Eides zusammen. Für die SPD zählte die Reform der Eidesformel, für Zentrumspolitiker der performative Akt des Schwörens selbst. Wären die Sozialdemokraten dieser Logik gefolgt, dann hätten sie den Eid als solchen zur Disposition stellen müssen. Als Staatspartei der Republik musste der SPD jedoch an Loyalität gegenüber ihrer Schöpfung gelegen sein.

2. Der Wandel der religiösen Eidesformeln vom Kaiserreich zur Weimarer Republik ergibt einen ambivalenten Befund. Auf der obersten Textebene sind starke Diskontinuitäten sichtbar. Die religiösen Formulierungen fielen weg. Die Mebrheitssozialdemokraten und die Linksliberalen meinten, damit den politischen Eid säkularisiert zu haben. Die Frage nach der Verpflichtungsstruktur des Eides ging über in die Frage der Auslegung der „Treue zur Verfassung“. Amt und Person werden im Eid bestätigt und zugleich verwandelt. Das ging in der Weimarer Republik nicht mehr auf. Die Treue zur Verfassung wurde herabgestuft zur „Beobachtung der Verfassung“ Eid in der Weimar Republik überhaupt zu etablieren. Die politische Eidpraxis beruhte auf einer Unbedingtheit zweiter Klasse.

Soweit die Diskontinuität. Mindestens genauso wichtig ist aber die Kontinuität zum Kaiserreich. Die Verpflichtungsstrukturen sowohl des promissorischen wie auch des assertorischen Eides waren bereits im Kaiserreich in eine tiefe Krise geraten. Der assertorische Gerichtseid verlor seine religiöse Aura in der alltäglichen Gerichtspraxis mit den explodierenden Vereidigungszahlen. Über den promissorischen Eid wurden Amtsinhaber zu Repräsentanten einer unpersönlichen Ämterordnung. Die Unbedingtheit des Eides stellte aber eine letztlich widersprïchliche Eidesformel her: Sie war zum einen allgemein-religiös (,so wahr mir Gott helfe"), zum anderen christlich-monotheistisch (der allmächtige und allwissende Gott). Die nachfolgenden Debatten kreisten um diesen Unterschied. Eine Antwort darauf war der teilweise erfolgreiche Versuch der Rekonfessionalisietung des Eides. Sie ging zusammen mit dem vehementen Antisemitismus so weit, dass die Verbindung von Eid und Amt, also die Konsekration zu einer personenungebundenen Ämterordnung prekär wurde. Die Konzentration auf die Trennung von Staat und Kirche hatte die Krise des Eides 1919 kurzfristig verdeckt.

Erst das Urteil des Bundesverfassungsgerichts vom 11. April 1972 schuf eine neue Differenzienung auf der performativen Ebene. Die Richter unterscbieden zwischen der bürgerlichen Bekräftigung, die für jedermann galt, der etwa den Zeugeneid leisten sollte, und dem Amtseid für das höhere politische Personal, wie den Bundespräsidenten und die Mitglieder der Bundesregierung. Diese hatten nach wie vor den Eid zu leisten, mit oder ohne religiöse Formel. Die von der säkularen Rechtsordnung erstrebte Gewissensbindung des Amtsträgers setzte auch nach 1949 den Eid voraus. In diesem Amtseid wird der ältere Treuebegriff, der die gewissensmäßige inhaltliche Übereinstimmung mit der Verfassung bezeichnete, ersetzt durch den Begriff des "Wahrens“. Dieses „Wahren“ ist mehr als das formale „Befolgen" oder „Beachten" der Weimarer Auslegung des Amtseides. Es liegt zwischen dem „Beobachten" des Weimarer Amtseides und dem persönlichen Treueeid des Kaiserreiches und des Nationalsozialismus. Es impliziert ein 
positives Eintreten für die Verfassung, ein Darüber-Wachen und Hüten der Verfassung. Andere Staaten sehen die Möglichkeit der bürgerlichen Bekräftigung im Amtseid vor. Die Vereinigten Staaten überlassen es dem gewählten Präsidenten, einen „oath“ oder eine "affirmation" abzulegen. Auch in Österreich wird der Bundespräsident durch ein Gelöbnis in sein Amt eingeführt, nicht durch einen Eid. ${ }^{89}$

3. Der politische Eid als Zugang zum Amtsgedanken war zentral für eine repräsentative Demokratie. Vor und nach 1918 wurde mit großer Vehemenz um Fragen des politischen Eides, seinen Wahrheitsgehalt und die dadurch begründete Treue gestritten. Über den Eid wurden in Deutschland offenbar besonders Fragen der Identitätspolitik ausgetragen. Auf die Identität zwischen dem Eidträger, der Eidesnorm, dem Eideshort und seinem Amt kam es an. Die Identitätsfrage machte die Eidfrage zum politischen Schlachtfeld. Aus diesem Zusammenhang stammte letztlich auch der klassische Amtsbegriff, der ebenfalls von Figuren der Identität zwischen Volk und politischem Amt ausging. Im 20. Jahrhundert aber hatte der Amtsbegriff seinen Ort in der repräsentativen und nicht in einer plebiszitären und identitätsfixierten Demokratie. Das Amt in der repräsentativen Demokratie basiert dagøgen stärker auf der Vorstellung des ,responsible government", was die Trennung von Amtsträgern und Volkssouverän voraussetzt. Das Vertrauen in die Amtsinhaber tritt an die Stelle der Identität mit einem Volkswillen. Es war also auch die starke Identitätspolitik mit den Eidesformeln, die die Transformation des Amtsbegriffes in ein System der repräsentativen Demokratie so lange hinauszögerte.

89 Vgl. Emst Friesenhahn, „Über den Anwaltseid im Rahmen der neueren Entwicklung des politischen Eides", in Bodo Brenner et. al. (Hrsg.), Einigkeit und Recht und Freiheit. Festschrift Karl Carstens (70), Köln 1984, Bd. 2, 570f; weitere Beispiele hierzu in: Stooß, Meineid, 127. 